\title{
SOCIAL PARTNER INVOLVEMENT IN LATVIA SPECIAL ECONOMIC ZONES
}

\author{
Ivo GULBIS ${ }^{1}$, Sanda GEIPELE ${ }^{2}$ \\ ${ }^{1,2}$ Riga Technical University, Latvia \\ Corresponding author e-mail: ivo.gulbis@edu.rtu.lv
}

\begin{abstract}
With increasing global competitiveness, countries must have instruments to attract and keep businesses. One way involves attracting a core of foreign investors with the help of special economic zones (SEZs) and integrating them in local economy, causing industrial clustering. The aim of this research is to lay the groundwork for a comprehensive analysis of clustering potential in Latvia via its special economic zones. The empirical research relied on survey results conducted among 27 business associations with the combined member count of over one thousand businesses, operating in 12 broad fields. Initial results gathered from the 24 organizations that responded to the interview questions show that there is a very low degree of involvement in the SEZ by various social partners. This shows that something has gone awry in the way SEZ operate in Latvia and has led to a lot of missed opportunities from both sides.
\end{abstract}

Keywords: Cluster, cooperation, social partners, special economic zones (SEZ). JEL Classification: R100 General Regional Economics

\section{INTRODUCTION}

Regional development is now a very topical issue in Latvia. The Bill on the creation of the new Latgale SEZ was passed at the end of 2015. The new SEZ has been established and will be joining the two existing ones - Rezekne and Liepaja SEZ. The state has devoted significant resources in an attempt to boost the overall economic development, but the activities had mixed success. The fact that the new SEZ was chosen as the most recent instrument, proves that the two existing ones have achieved good results. The overall most successful, Liepaja SEZ, includes 38 businesses, with total revenue of 168 million Euro, half of which comes from export, and 2043 workers. However, it should be noted that Liepaja SEZ includes also a port, thus the majority of all the revenue does not come from traditional manufacturing. Meanwhile Rezekne SEZ includes 18 businesses with total revenue of 70.5 million Euro, of which 18.5 million Euro comes from export, 811 workers and more than half of all the foreign direct investment in the regional district. There are high hopes that the new SEZ will be able to achieve similar results in Latgale region which traditionally has been lagging behind in development.

When it comes to cluster development, the research by Kulakova \& Volkova (2013) shows that there is still a lot of work to be done. The research results demonstrate that while there have been dozens of cluster initiatives launched by the state, a survey of a number of cluster representatives revealed that the majority of them were very critical of the cluster policy in Latvia. Since then years have passed and according to the Global Competitiveness Report 2016-2017 Latvia is in the $90^{\text {th }}$ place in the state of cluster development. That is 9 places higher than in 2013, indicating that there has been some improvement. However, it is still a place in the bottom of the list of 144 world nations and signals that there is a need for major improvement. 
The aim of this research is to lay the groundwork for a comprehensive analysis of clustering potential in Latvia via its special economic zones. For several first studies, the research object is business ties between Latvian SEZs and Latvian businesses. The research subject is cluster facilitation. The results of the research can be used to determine further enhancement in both SEZ and cluster policy, as well as to define further areas of the research.

To achieve the aim of the research, a number of research methods were used: qualitative and quantitative, synthesis and analysis, induction and deduction, logically constructive method, data collection and analysis, sociological research methods - the analysis of documents as well as a questionnaire.

This article consists of three sections. In Section 1 the authors review scientific literature to analyze the importance of both SEZ and clusters. In Section 2 the findings of the surveys of 27 major business associations and the representatives of Liepaja and Rezekne SEZ conducted by the authors are presented and analyzed. Section 3 presents the conclusions and recommendations for further research.

\section{SCIENTIFIC LITERATURE REVIEW}

SEZ can be the means if clustering is set as the goal. As noted by Zeng (2015), SEZ can be a very powerful tool if used in a right way, as evidenced by emerging economies all over the world, particularly in China,

However, there is more to do with SEZ to maximize their benefits. A working SEZ provides a lot of businesses in one area and thus creates a potential for future clustering. Clusters consist of companies, suppliers and service providers, as well as government agencies and other institutions that provide education, information, research and technical support to a regional economy (Slaper \& Ortuzar, 2015).

Clusters are one of regional development tools, much like special economic zones. Their presence indicates a healthy business environment in the form of good infrastructure, cooperative businesses, an established supply chain and good governmental policies. As such, the very presence of clusters can tell us quite a bit about any given region. The identification of clusters is a valuable tool for understanding regional economies and implementing successful development strategies (Argüelles, Benavides \& Fernández, 2014).

Whenever any given region manages to create a cluster, it invariably gives the region an edge against local competition when it comes to attracting new businesses in the field. Clusters are a path to the enhancement of competitive advantages. The government should construct economic zones with cluster characteristics in an effort to enhance industry competitiveness (Hsu, Lai \& Lin, 2013).

Of course, there are many reasons why businesses would want to participate in clusters. Clusters reduce uncertainty and provide access to necessary resources (financial capital and competence/knowledge) in crises periods (Skålholt \& Thune, 2013). It is not just in crisis periods, but in times of economic uncertainty as well, when market growth is not guaranteed. During these times, the difference between having access to a cluster's resources and not having them can decide whether a company survives or fails.

All of cluster's participants benefit from it, regardless of their size. It is a common thought that clustering really attracts and benefits only the large companies, but research disputes that claim. The findings demonstrate that the more small-medium the firm is, the more extensive knowledge-sharing should be, which is quite contrary to the empirical phenomena of lacking knowledge-sharing in SMEs for their less resources and attention dedicated to it (Chen, Wang, Chang, \& Hung, 2014). 
Considering the listed benefits, it is easy to understand why policy makers devote significant energy to try and encourage company clustering. When clustering is encouraged by the government with the help of policies, it is called a top-down approach to clustering. A cluster can also occur naturally, spurred by the initiative of the companies themselves. That is called a bottom-up approach. European countries have plenty of examples of both top-down and bottom-up cluster formation routes; there is no universal and ideal approach that would fit all cases (Maticiuc, 2014).

It is important to remember that for clustering to occur, more than just policies and good intentions are needed. The basic requirement for creating clusters is plenty of companies that are innovative and competitive by themselves. The effort of some regions and countries to create a strong cluster in modern sectors without taking into account the real situation mostly ends with failure despite large financial injections (Littvova, 2014).

There are other details to consider as well. Cluster's type and geographical location might influence what sort of firms flock to it (Tracey, Heide, Bell, \& Governance, 2014). In this regard, everything matters. Different businesses might prize different things. For some, it's purely about geographical location and the speed at which they can move their products to the markets. For more R\&D heavy firms it could be about the density of connections among the cluster's constituents. Taking all of the variables into account trying to encourage the formation of a cluster is a very challenging and daunting prospect for cluster facilitators.

Cluster facilitators in potential clusters try to establish a platform for these clusters to stand on in terms of building cohesion and improving framework conditions. In latent clusters, the focus is on initiating cooperative activities to foster interaction and improve the critical mass. Finally, cluster facilitators in working clusters try to facilitate business creating activities and enlarge the sphere of these clusters (Ingstrup \& Damgaard, 2011).

Cluster facilitation is not possible without public support. Public support - due to so called external effects - benefits the whole cluster including cluster entities that are not part of the initiative. It is therefore proposed that future cluster policies include support for clusters in broad areas of activity, e.g. R\&D, international expansion, stimulating sector cooperation and creation of new enterprises (Koszarek, 2014).

It should be noted that Latvia in particular needs to do a lot in order to improve the existing situation. Although in last ten years dozens of clusters initiatives have been launched in Latvia and several support programs co-financed by the ERDF were created directly and indirectly concerning cluster activities, generally the cluster policy in Latvia is poorly developed in comparison with the desired state and best practices in Europe (Kulakova \& Volkova, 2013).

However, a cluster cannot really be created only by encouragement. Companies need to see the benefits and join together voluntarily. Without that interest and the resulting direct and indirect cooperation there will be no cluster.

\section{METHODOLOGICAL SOLUTION}

In order to ascertain the amount of interest and possible cooperation between Latvian SEZ and local businesses, a two part survey was conducted. For the first survey, a number of relevant employer associations were selected and approached (Survey 1). In the second survey, the management of Rezekne and Liepaja SEZ were asked to respond to a set of questions (Survey 2). The aim of Survey 1 was to find out the number of local businesses cooperating with the investors in both existing Latvian SEZs, how close the cooperation is and whether or not the respondents see the benefit in adding more local partners into their existing collaborative networks with the foreign investors. The aim of Survey 2 was to find 
out how involved both SEZs are in facilitating cooperation between their investors and local businesses.

The target group of Survey 1 consisted of spokespeople of 27 business associations who were asked to forward the survey questions to their association members or to respond on their behalf, if they felt that they could, either due to the small membership or cohesion. The surveyed business associations represent 12 broad fields and their task is to promote the interests of their members both nationally and internationally. The wide range was chosen on purpose in order to find as many possible links as possible. The target group of Survey 2 consists of the governing bodies of the two existing Latvian SEZs - Liepaja and Rezekne SEZ.

The survey method used was WAPI (Web Assisted Personal Interview) consisting of both closed and half open questions.

The sampling amount depended on how many associations felt confident enough to answer on behalf of their member organizations in Survey 1. It was possible that there were only a few responses, if just a few associations participated in the survey; it was possible also to have well over a thousand responses, should most individual members choose to answer. In Survey 2, only two responses were expected.

The survey was conducted from July 2016 through October 2016.

\section{RESULTS AND DISCUSSION}

When it comes to the sample size, the surveyed 27 associations have a total member count of over 1000 and represent a significant chunk of businesses within their respective fields. From all the potential respondents, only 24 chose to answer the survey questions 22 of those were individual businesses and 2 were associations confident enough that they could answer on behalf of their members. Altogether, the actual respondents represented 8 fields and roughly 500 businesses, since the two associations responded on behalf of their members. For a more detailed breakdown of represented business fields see Fig. 1.

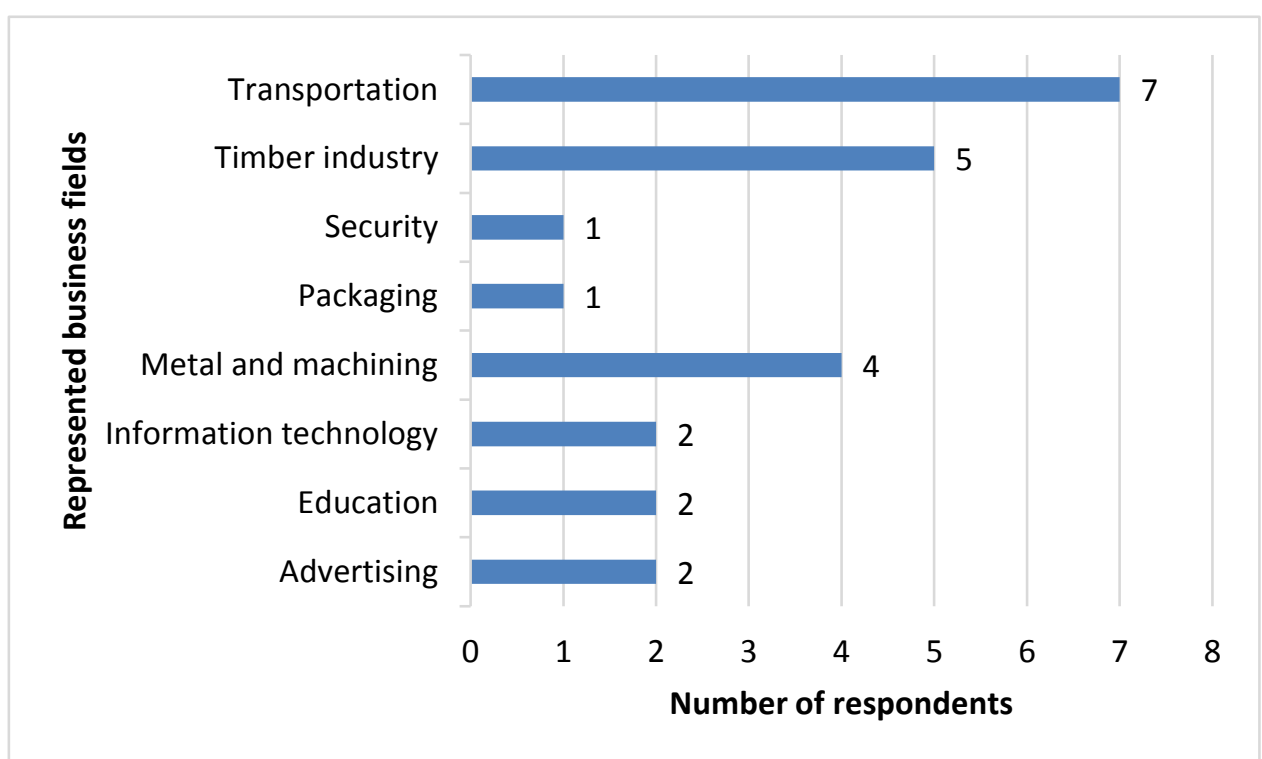

Fig. 1. The breakdown of represented industries. [Developed by authors]

The first thing that should be noted is that the transportation field is by far the most widely represented (see Fig. 1), since one of the associations that responded was "Latvijas 
Auto", the leading transport association in Latvia with roughly 459 members. The second association to respond was "The Packaging Association of Latvia" with 19 members. Not to distort Fig. 1, both associations are counted as a single respondent even though they have responded on behalf of all their members.

When respondents were asked whether they cooperated with either of the Latvian SEZ, none gave a positive answer. A negative answer to the very first question by all respondents made meaningless further few questions about the nature of the cooperation and how it developed. The entire purpose of the survey was shifted from exploring the degree of social partners' involvement with the Latvian SEZ to finding out why the involvement does not exist.

When asked the next question about the reasons why there is no cooperation between the involved parties, all 24 respondents chose the answer saying that they had no information about what services the SEZ needed. None of them thought that their field was too specific for cooperation. None of them could claim that an offer was made by either side and then denied by the other side. Not a single one used a chance to give another reason. All answers pointed to a simple lack of information about what is needed for cooperation.

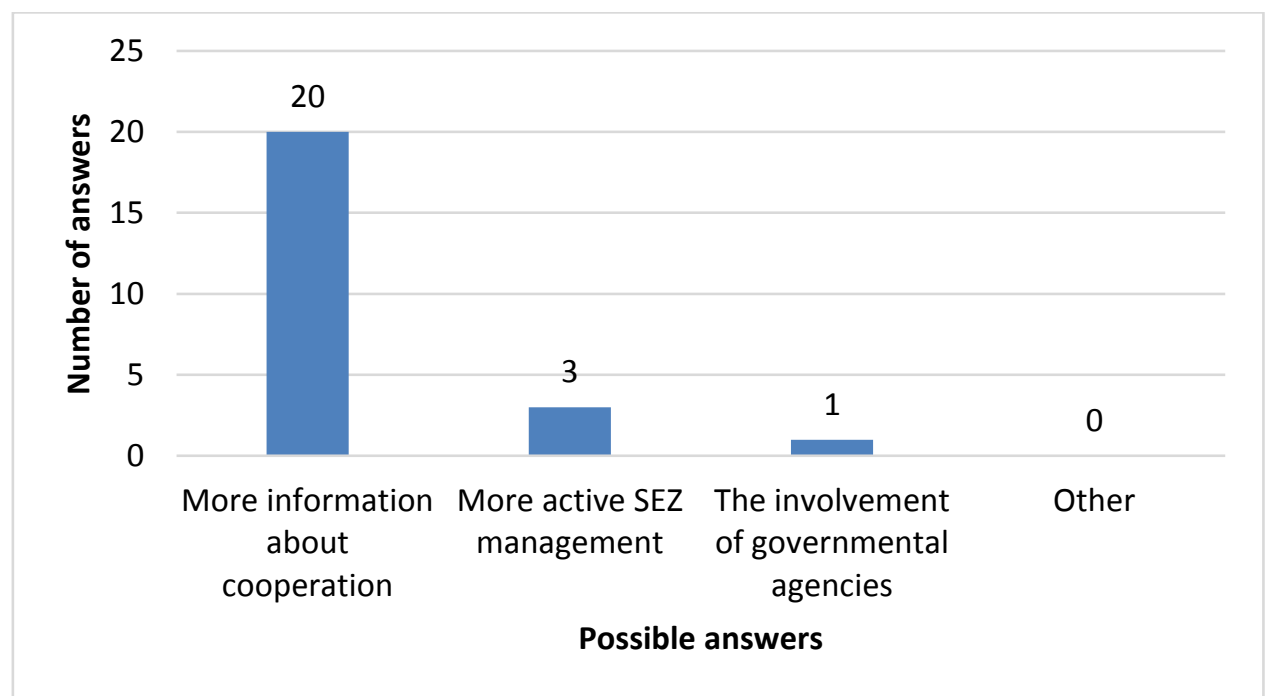

Fig. 2. What in your opinion, can be done to develop closer cooperation between local businesses and SEZ? [Developed by authors]

The next question was whether the respondents wished to cooperate with the SEZ. All 24 respondents replied affirmatively. The last question asked was: what could be done to develop closer cooperation between Latvian businesses and SEZ. The overwhelming majority of respondents, 20 of them, expressed the need for more information. Three of the respondents wished for a more active involvement from the side of the SEZ management in approaching local business about what their foreign investors need. One thought that involving governmental agencies would help the situation. None chose to make their own suggestions. For details, see Fig. 2.

Although the surveyed businesses and associations did not have any contact with the SEZ, it was possible that they did not have information on the situation as a whole. To ensure that the research is thorough, the management of Rezekne and Liepaja SEZ were approached with questions about what was done to encourage the cooperation between investors and local businesses. Spokespeople of both SEZs mentioned that they had no 
statistics on the degree of cooperation between investors and local businesses. It was also said that their involvement in these matters was minimal and usually limited to directing questions to the respective government agency, without taking any active role in the process.

As for government programs, there exists "POLARIS process" which is meant to assist investors in all matters, including finding local business contacts. This program is run and administered by the Investment and Development Agency of Latvia and is presumed to be the main instrument with which the state facilitates collaboration between local businesses and foreign investors.

The results of the surveys, conducted from July 2016 through October 2016, show us that, as of now, there is no involvement of the surveyed businesses with the foreign investors present in Rezekne and Liepaja SEZ. In total that is 24 businesses working in 8 broad fields that have not had a chance to establish business relationships with foreign investors. When asked for the reason why no business relationships existed, all of the respondents said that they were not aware of what the SEZ needed. Considering that later on they also said that they did look forward to future cooperation with the SEZ, it can be concluded that little stands in the way of the facilitation of business ties. There is a disconnect in the existing system, where the local business associations seem to be left in the dark about what sort of foreign investors Latvia has, what fields they work in and what they need. The one policy instrument that was referenced, the "POLARIS process" seems to be reactive in its nature rather than proactive. It is possible that the whole system would work better if it were local business associations that get notified first of any foreign investor presence, who could then disseminate the information to their members and encourage the creation of healthy business ties.

From the results of the survey a few assumptions about the nature of investments in both existing SEZs can be made. First of all, it should be noted that transport industry is well represented both in survey and in Latvia's economy. The surveyed members of the transportation industry mostly dealt with road transport, indicating that most of the manufactured goods that come out of the SEZ must be meant for export via railways and ports. Considering that Liepaja SEZ is a port, while Rezekne SEZ offers an easy access to a railway hub, it can be concluded that the claim makes sense and both SEZs were placed in appropriate places, since the investors are actively using the proximity to both modes of transportation.

Secondly, there is an issue of the education sector. Training and retraining workers is an important part of any existing SEZ. Businesses can come and go, one skillset can become obsolete while another comes in high demand. Two organizations affiliated with the professional education sector participated in the survey and had no contacts with the SEZ. This indicates that the skillset desired by the foreign investors in the SEZ must be either widespread or easily attainable, likely meaning that the products manufactured are not with high added value. It could also mean that so far, the education sector has been mostly left out when it comes to collaboration between businesses. Considering that the education sector is one of the three most important constituents of a cluster, alongside business and the state, this issue should be addressed by a more comprehensive policy in the future.

\section{CONCLUSION}

Regional development is an ever topical question for every policymaker. When two regional development tools in the form of SEZ and industrial clusters have a good synergy, there is a powerful incentive to use them both together. This research is about laying the groundwork for a comprehensive analysis of clustering potential in Latvia via its special 
economic zones. Finding out how strong are the links between Latvian SEZs and local businesses is only the first step. The research demonstrated that the link is practically nonexistent. None of the respondents had any link with the SEZ, nor did the SEZ management do anything to facilitate such connections.

The only thing that could be gathered about building connections was that the program dealing with it is in the hands of a separate agency. While there is nothing wrong in particular with having the investment policy in the hands of a single government agency, the respondents expected for the SEZ management to be the link between the investors they have attracted and the local businesses. From the investor's point of view it is convenient to deal with a single organization when it comes to establishing their operation in a new country. In a world increasingly oversaturated with SEZs and tax breaks, it is the quality of service in regards to details that can decide the place that gets investment and the place that is left with nothing.

Lessons learned are especially topical now because Latvia intends to open the third Latgale SEZ. If there are no lessons learned from the two existing ones, there is no point in expecting a different outcome to what Latvia has right now. With good policies and incentives, it is possible to start a clustering effect. Unfortunately, the cornerstone of clustering, to begin with, is interaction of businesses - which does not exist between Latvian SEZs and local business associations, making it very difficult for any potential clustering to occur.

This research looked at things from the perspective of local business associations, with another set of questions directed towards the SEZ to confirm the findings. In order to fully understand the clustering potential that could be achieved via tested and true regional development tools in the form of SEZ, further research needs to be done. The next step should be to consider the existing situation from the perspective of state programs and relevant government agencies. State actors have very different view from that of the private, it is possible to miss the intent and the results of that intent when looking only from one point of view.

\section{REFERENCES}

Argüelles, M., Benavides, C., \& Fernández, I. (2014). A new approach to the identification of regional clusters: hierarchical clustering on principal components. Applied Economics, 46(21), 2511-2519. https://doi.org/10.1080/00036846.2014.904491

Chen, M. H., Wang, H. Y., Chang, Y. Y., \& Hung, A. (2014). Knowledge sharing, social capital and firm performance in technological clusters of Taiwan Science Parks: An innovation strategy perspective. 2014 Portland International Center for Management of Engineering and Technology, PICMET 2014, 1040-1054. Retrieved from http://www.scopus.com/inward/record. url?eid=2-s2.0-84910128544\&partnerID=40\&md5=30cdb94c178f6643b305c4c69e5c9fe0

Hsu, M.-S., Lai, Y.-L., \& Lin, F.-J. (2013). Effects of Industry Clusters on Company Competitiveness: Special Economic Zones in Taiwan. Review of Pacific Basin Financial Markets and Policies, 16(3), 1350017. https://doi.org/10.1142/S0219091513500173

Ingstrup, M. B., \& Damgaard, T. (2011). Cluster Facilitation from a Cluster Life Cycle Perspective. IMP 2011 Conference, 21(4), 1-19. https://doi.org/10.1080/09654313.2012.722953

Koszarek, M. (2014). Supporting the development of clusters in Poland - dilemmas faced by public policy. Prace Naukowe Uniwersytetu Ekonomicznego We Wrocławiu, (365). https://doi.org/10.15611/pn.2014.365.08

Kulakova, N., \& Volkova, T. (2013). Evaluation of Cluster Policy in Latvia. Journal of Business Management, (7), 83-92. Retrieved from http://0-search.ebscohost.com.millenium.itesm. $\mathrm{mx} /$ login.aspx direct $=$ true $\& \mathrm{db}=\mathrm{bth} \& \mathrm{AN}=93708118 \&$ site=ehost-live $\&$ scope $=$ site

Littvova, V. (2014). The Slovak Republic Regional Development through Cluster Iniciative. Creative and Knowledge Society, 4(2). https://doi.org/10.2478/cks-2014-0009 
Maticiuc, L. (2014). Top-Down and Bottom-Up Cluster Initiatives in Europe, 14(1), 205-212.

Skålholt, A., \& Thune, T. (2013). Coping with Economic Crises-The Role of Clusters. European Planning Studies, 22(10), 1993-2010. https://doi.org/10.1080/09654313.2013.813909

Slaper, T., \& Ortuzar, G. (2015). Industry Clusters and Economic Development. Indiana Business Review, 7-9.

Tracey, P., Heide, J. B., Bell, S. J., \& Governance, P. (2014). Bringing “ Place” Back In : Regional Clusters, Project Governance, and New Product Outcomes. Journal of Marketing, 78(November), 1-16. https://doi.org/10.1509/jm.13.0524

Zeng, D. Z. (2015). Global Experiences with Special Economic Zones Focus on China and Africa. World Bank Policy Research Paper, (WPS7240), 1-17.

\section{AUTHORS' SHORT BIOGRAPHIES}

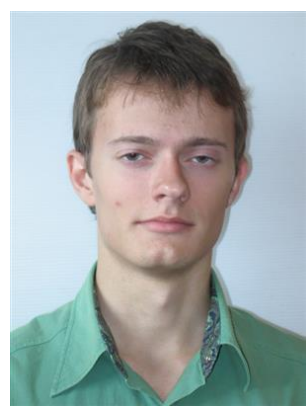

Ivo Gulbis, Mg. oec., is a Assistant Researcher and a PhD student with Riga Technical University, Latvia. He obtained the Master's and Bachelor's degree in customs and tax administration from RTU. His $\mathrm{PhD}$ studies are in management and economics at Riga Technical University. He has work experience as an Assistant to a Member of the Parliament of Latvia and as a participant in multiple studies about the business environment of Latvia. Since 2015, he has participated in scientific conferences, congresses and workshops. His current research interests are special economic zones and industrial clusters.

ORCID iD: http://orcid.org/0000-0001-9274-3466

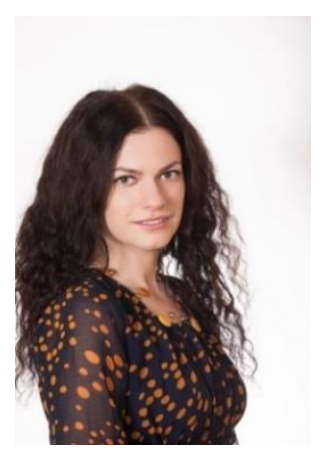

Sanda Geipele, Dr. oec., is a Lead Researcher and Assistant Professor at Riga Technical University, Latvia. For more than 5 years she has worked as a Chief Economist at the Municipal Revenue Department of Riga City Council and her work was related to real estate tax administration. Her research interests are: sustainability development problems of real estate market, construction industry, including land use management and institutional economics. She is the author and co-author of more than 56 scientific publications, including scientific monograph "Management System of Real Estate Market Development in Latvia" (2015), two monographs with co-authors "Models of Financing Housing Fund Renovation in Latvia" (2012), "Socio-Economic Aspects of the Interaction of Urban and Regional Development" (2012). Since 2010, she has participated in more than 16 scientific conferences and 6 international scientific and practical projects. She is an expert in management and economic sciences of the Latvian Council of Science.

ORCID iD: http://orcid.org/0000-0002-4721-5944 